\title{
Penerapan Data Mining Terhadap Data Penjualan Lapis Bogor Sangkuriang Dengan Metode Algoritma Apriori
}

\author{
Bella Audi Najib ${ }^{1}$, Nining Suryani² \\ ${ }^{1}$ Program Studi Sistem Informasi \\ STMIK Nusa Mandiri Jakarta \\ J1. Damai No. 8, Warung Jati Barat, Pasar Minggu, Jakarta Selatan \\ bellaaudinajib@gmail.com \\ ${ }^{2}$ Program Studi Sistem Informasi Kampus Kabupaten Karawang \\ Universitas Bina Sarana Informatika \\ Jl. Kamal Raya No. 18 Ringroad Barat, Cengkareng, Jakarta Barat \\ nining.nns@bsi.ac.id

\begin{tabular}{ccc}
\hline Diterima & Direvisi & Disetujui \\
$23-10-2019$ & $19-12-2020$ & $31-01-2020$ \\
\hline
\end{tabular}

\begin{abstract}
Abstrak - Penentuan pola pembelian barang dan tata letak barang berdasarkan kencenderungan konsumen membeli barang dapat menjadi salah satu solusi bagi Toko Lapis Bogor Sangkuriang dalam pengembangan strategi pemasaran sehingga dapat meningkatkan penjualan produk Lapis Bogor Sangkuriang. Algoritma yang dapat digunakan untuk penentuan pola pembelian barang dan tata letak ini adalah Algoritma Apriori yang merupakan salah satu algoritma data mining dalam pembentukan asosiasi rule mining. Dengan frequent item/itemset pada algoritma apriori dengan menghasilkan frequent yang sedikit, tanpa melakukan candidate generation dan meminimalkan tahapan penyelesaian yang dimulai pada k-1 item atau tahapan pertama pada algoritma apriori selanjutnya digunakan dengan metode FP-Growth dimana metode ini sangat signifikan dengan algoritma apriori, efesien dari segi waktu, tahap penyelesaian lebih cepat, sedikit menghasilkan pattern frequent item/itemset dan lebih terperinci dalam memaparkan hasil frequent item karena hasil frequent yang bernilai $<1$ masih diperlihatkan, tidak di hapus. Penelitian ini menghasilkan Produk yang paling banyak terjual untuk kue lapis adalah Original Keju, Brownies Keju, Full Talas. Berdasarkan aturan asosiasi final yang diketahui jika membeli kue Lapis Bogor Sangkuriang varian Original Keju maka akan membeli Lapis Bogor Sangkuriang varian Brownies Keju dan Full Talas Keju dengan nilai support 30\% dan nilai confidence 70\%. Berdasarkan hasil inilah perusahan dapat mengambil keputusan pengembangan strategi yang dilakukan selanjutntya.
\end{abstract}

\section{Kata Kunci: Algoritama Apriori, FP-Growth, Asosiasi Rule Mining}

\begin{abstract}
Determination of the pattern of purchasing goods and layout of goods based on the tendency of consumers to buy goods canbe one solution for the Bogor Sangkuriang Lapis Shop in developing marketing strategies so as to increase sales of Lapis Bogor Sangkuriang products. The algorithm that can be used to determine the pattern of purchasing goods and this layout is the Apriori Algorithm which is one of the data mining algorithms in the formation of rule mining associations. With frequent items in a priori algorithm by producing a small frequent, without doing candidate generation and minimizing the completion stages starting at $k-1$ items or the first stage in the a priori algorithm then used with the FP-Growth method where this method is very significant with the a priori algorithm, efficient in terms of time, the completion stage is faster, produces less frequent items and is more detailed in describing frequent item results because frequent results with a value $<1$ are still shown, not deleted. This research produced the most sold products for layer cakes are Original Cheese, Cheese Brownies, Full Talas. Based on the rules of the final association, it is known that if you buy the Bogor Sangkuriang Lapis Original Cheese cake layer, you will buy the Lapis Bogor Sangkuriang Brownies Cheese and Full Talas Cheese with a support value of $30 \%$ and a confidence value of $70 \%$. Based on these results the company can make the decision to develop a strategy that is done next.
\end{abstract}

Keywords: Apriori Algoritama, FP-Growth, Rule Mining Association 


\section{PENDAHULUAN}

Kota Bogor merupakan salah satu destinasi pariwisata di Jawa Barat juga memiliki kuliner yang sangat beragam. Banyak UMKM di Bogor pada sektor makanan berlomba untuk mengolah makanan semenarik mungkin untuk menarik minat beli konsumen. Beberapa contoh UMKM di Bogor yang mulai berkembang adalah Macroni Panggang, Choco Lava, Roti Unyil Venus, Lapis Bogor Sangkuriang Pizza Meteran, dan masih banyak lagi. LAPIS BOGOR SANGKURIANG hadir dengan produk olahan makanan lapis bolu berbahan dasar talas yang sangat inovatif.

Rasa dan kualitas menjadi prinsip utama LAPIS BOGOR SANGKURIANG terhadap produknya. Sejak berdiri pada 2011, LAPIS BOGOR SANGKURIANG telah mampu memikat banyak pecinta kuliner di Bogor. Persaingan diantara industri makanan olahan khususnya produk oleholeh khas daerah menjadi suatu tantangan tersendiri bagi para pelaku usaha untuk mampu mempertahankan eksistensi usahanya. Posisi LAPIS BOGOR SANGKURIANG yang sedang dalam masa tumbuh memerlukan strategi promosi yang tepat yang dapat digunakan untuk mempertahankan bahkan mengekspansi konsumennya sehingga penjualan LAPIS BOGOR SANGKURIANG akan terus meningkat.

Semakin pesat pertumbuhan makanan dikalangan masyarakat mengakibatkan seringnya LAPIS BOGOR SANGKURIANG melakukan inovasi dari segala macam pilihan rasa. Pemilihan jenis rasa makanan yang diminati masyarakat menjadi salah satu hal yang sangat berpengaruh dalam penjulan makanan. Didunia penjualan, LAPIS BOGOR SANGKURIANG dituntut agar dapat menemukan suatu formula yang dapat meningkatkan penjualan produk dipasar. Salah satu cara yaitu dengan memanfaatkan data penjualan produk makanan. Dengan menggunakan data yang diperoleh setiap hari dapat dimanfaatkan dan diolah menjadi suatu informasi yang berguna untuk peningkatan penjualan dan promosi produk makanan.

PT. Agrinesia Raya Indonesia yang didirikan semenjak tahun 2011 menjadi salah satu produsen yang pertama dan terbesar di kota Bogor dalam menggunakan bahan dasar utama tepung talas, dengan KUE LAPIS TALAS BOGOR yang diberi nama LAPIS BOGOR SANGKURIANG menjadi produk utama dari perusahaan ini memiliki kekhasan pada rasa dan tekstur kue yang lembut menjadi komitmen dalam mengembangkan usaha produk makanan hingga layak dijadikan oleh-oleh khas Bogor. Dengan melakukan Standard Food Safety System untuk menjamin terjaganya kualitas kue dan mutu serta higienis serta didukung oleh tenaga kerja berkompeten menjadikan PT. Agrinesia Raya Indonesia sebagai produsen makanan yang diterima baik oleh khalayak umum dari berbagai kalangan. Produk makanan kami telah teruji Sertifkasi Halal Oleh MUI.

Dalam pemasaran suatu produk ada beberapa faktor akan sangat berpengaruh terhadap penjualan, salah satunya adalah strategi dalam penjualan. Dengan strategi yang bagus sebuah produk akan terjual dengan cepat, namun jika strategi yang di gunakan tidak tepat maka suatu produk akan menurun dari segi penjualan. (Hidayat \& Wijanarto, 2017)

Agar memudahkan mengolah data yang telah ada dengan jumlah yang sangat banyak, digunakan data mining. Dengan menggunakan data mining maka akan didapatkan suatu pengetahuan didalam kumpulan data-data yang banyak tersebut. Salah satu penerapan data mining adalah dibidang penjualan produk. Hal ini dilakukan agar sasaran penjualan produk makanan tepat dan tidak menghabiskan banyak waktu dan biaya dalam memilih target produk yang diminati masyarakat.

Pengolahan data untuk memperoleh informasi mengenai pola-pola dapat dilakukan dengan data mining, yaitu Association Rules. Algoritma Apriori yang merupakan salat satu metode Association Rules cocok untuk diterapkan bila terdapat beberapa hubungan item yang ingin dianalisis (Aprianti, Permadi, \& Oktaviyani, 2017)

Penelitian dengan penerapan algoritma apriori yang dilakukan dapat menemukan sejumlah aturan asosiasi dari basis data transaksi penjualan produk buku di percetakan PT.Gramedia dan dapat digunakan sebagai pertimbangan dalam pembuatan strategi pemasaran dan penjualan. (Gunadi \& Sensuse, 2012)

Penerapan algoritma aproori juga dapat di terapkan pada penjualan ttiket pesawat mengetahui hubungan pola frekuensi penjualan tiket pesawat yang paling sering di beli oleh konsumen. (Siregar, 2014)

1. Penerapan Algoritma Apriori dapat juga untuk membantu dalam membentuk calon kombinasi item, kemudian dilakukan pengujian apakah kombinasi tersebut memenuhi parameter support dan confidence minimum yang merupakan nilai ambang yang diberikan oleh peneliti. Jika memenuhi parameter support dan confidence maka hasil tersebut dapat membantu dalam penentuan pola pembelian barang dan membantu tata letak barang berdasarkan kencenderungan konsumen membeli barang. Masalah yang diidentifikasi pada Toko Lapis Bogor Sangkuriang adalah bagaimana pengembangan strategi pemasaran untuk meningkatkan penjualan produk Lapis Bogor Sangkuriang.. 


\section{METODOLOGI PENELITIAN}

A. Pengertian Data Mining

Nama data mining sebenarnya mulai di kenal sejak tahun 1990, ketika pekerjaan pemanfaatan data menjadi sesuatu yang penting dalam berbagai bidang, mulai dari bidang akademik, bisnis, juga medis.

Proses perulangan dan interaktif untuk menemukan pola-pola atau model baru yang shahih (sempurna), berguna dan bisa dimengerti dalam suatu database yang sangat besar (massive databases) merupakan salah satu kegunaan data mining. Data mining mengandung pencarian trend atau pola yang diinginkan dalam database besar untuk membantu pengambilan keputusan di waktu yang akan datang. (Syahdan \& Sindar, 2018)

Data mining merupakan istilah yang digunakan untuk menguraikan penemuan pengetahuan didalam database. Data mining adalah suatu proses yang mengenakan teknik statistik, matematika, kecerdasan buatan, dan machine learning untuk mengekstraksi dan mengidentifikasi informasi yang berguna dan pengetahuan yang terkait dari berbagai macam database besar (Nursikuwagus \& Hartono, 2016)

Data mining yaitu proses yang memperkerjakan satu atau lebih teknik pembelajaran komputer (machine learning) untuk menganalisis dan mengektraksi pengetahuan (knowledge) secara otomatis. (Halim, 1917)

Menurut Kusrini and Taufiq dalam (Rahmawati \& Merlina, 2018) Definisi umum dari data mining itu sendiri adalah proses pencarian pola-pola yang tersembunyi (hidden patern) berupa pengetahuan (knowledge) yang tidak diketahui sebelumnya dari suatu sekumpulan data dimana data tersebut dapat berada di dalam database, data werehouse, atau media penyimpanan informasi yang lain.

Menurut Hermawati dalam (Rahmawati \& Merlina, 2018) Data mining dibagi menjadi beberapa kelompok berdasarkan tugas yang dapat dilakukan yaitu:

1. Deskripsi: Terkadang peneliti dan analis secara sederhana ingin mencoba mencari cara menggambarkan pola dan kecenderungan yang terdapat didalam data.

2. Estimasi: Estimasi hamper sama dengan klasifikasi, kecuali variabel target estimasi lebih kearah numerik daripada kearah kategori.

3. Prediksi: Prediksi hampir sama dengan klasifikasi dan estimasi, kecuali bahwa dalam prediksi nilai dari hasil akan ada di masa mendatang.

\section{B. Algoritma Apriori}

Menurut Dan Toomey dalam

(Ristianingrum \& Sulastri, 2017), Apriori adalah algoritma kelas yang membantu mempelajari peraturan asosiasi. Ini bekerja melawan transaksi. Algoritma mencoba untuk menemukan himpunan bagian yang umum dalam kumpulan data. Ambang batas minimum harus dipenuhi agar asosiasi dapat dikonfirmasi.

Menurut (Sianturi, 2018) Algoritma apriori adalah algoritma paling terkenal untuk menemukan pola frekuensi tinggi. minimum support. Sedangkan pola frekuensi tinggi ialah pola item yang ada pada suatu database dimana mempunyai frekuensi atau support di atas ambang batas tertentu yang disebut dengan istilah

Menurut (Sianturi, 2018) Algoritma apriori dibagi menjadi beberapa tahap yang disebut iterasi atau pass yaitu:

1. Pembentukan kandidat itemset, kandidat kitemset dibentuk dari kombinasi (k-1)-itemset yang didapat dari iterasi sebelumnya. Satu cara dari algoritma apriori adalah adanya pemangkasan calon k-itemset yang subsetnya yang berisi $\mathrm{k}-1$ item tidak termasuk dalam pola frekuensi tinggi dengan panjang $\mathrm{k}-1$.

2. Penghitungan support dari tiap kandidat kitemset. Support dari tiap calon k-itemset didapat dengan melakukan scan database yang bertujuan untuk menghitung jumlah transaksi yang memuat semua item di dalam kandidat $\mathrm{k}$-itemset tersebut. Ini merupakan ciri dari algoritma apriori dimana diperlukan penghitungan dengan scan seluruh database sebanyak kitemset terpanjang

3. Tetapkan pola frekuensi tinggi. Pola frekuensi tinggi yang megandung $\mathrm{k}$ item atau $\mathrm{k}$-itemset ditetapkan dari calont k-itemset yang supportnya lebih besar dari minimum support.

4. Bila tidak didapat pola frekuensi tinggi baru maka seluruh proses dihentikan. Bila tidak, maka $\mathrm{k}$ ditambah satu dan kemabali ke bagian 1 .

Tahapan ini untuk mencari kombinasi item yang memenuhi syarat minimum dari nilai support dalam database. Nilai support sebuah item diperoleh dengan menggunakan rumus berikut:

support $A=$ jumlah transaksi berisi $A$ total transaksi

Sementara, nilai support dari 2 item didapatkan dengan menggunakan rumus :

\section{suppotr $A, B=P A \cap B$ \\ support $A, B$ \\ $=\sum$ transaksimengandung Adan $B$ Etransaksi}

Frequent itemset menunjukkan itemset yang memiliki frekuensi kemunculan lebih dari nilai minimum yang ditentukan $(\varnothing)$. Misalkan $\emptyset=2$, maka semua itemsets yang frekuensi kemunculannya lebih dari atau sama dengan 2 kali disebut frequent.Himpunan dari frequent kitemset dilambangkan dengan Fk. 


\section{TANAGRA}

Tanagra adalah software data mining bebas untuk tujuan akademik dan penelitian. Ini mengusulkan beberapa metode data mining dari analisis eksplorasi data, pembelajaran statistik, pembelajaran mesin dan daerah database. Tanagra adalah proyek open source karena setiap peneliti dapat mengakses ke kode sumber, dan menambahkan algoritma sendiri, sejauh dia setuju dan sesuai dengan lisensi distribusi perangkat lunak.

Tujuan utama dari proyek tanagra adalah memberikan peneliti dan mahasiswa yang mudah untuk menggunakan perangkat lunak data mining, sesuai dengan norma-norma yang hadir dari pengembangan perangkat lunak dalam domain ini (terutama dalam desain GUI dan cara untuk menggunakannya), dan memungkinkan untuk menganalisa baik data yang nyata atau sintetis.

Tujuan kedua tanagra adalah untuk mengusulkan kepada peneliti arsitektur yang memungkinkan mereka untuk dengan mudah menambahkan metode data mining mereka sendiri, untuk membandingkan kinerja mereka.

(Sumber:http://www.peric.univ-

lyon2.fr/ ricco/tanagra/en/tanagra.html).

\section{HASIL DAN PEMBAHASAN}

A. Kerangka Pemikiran

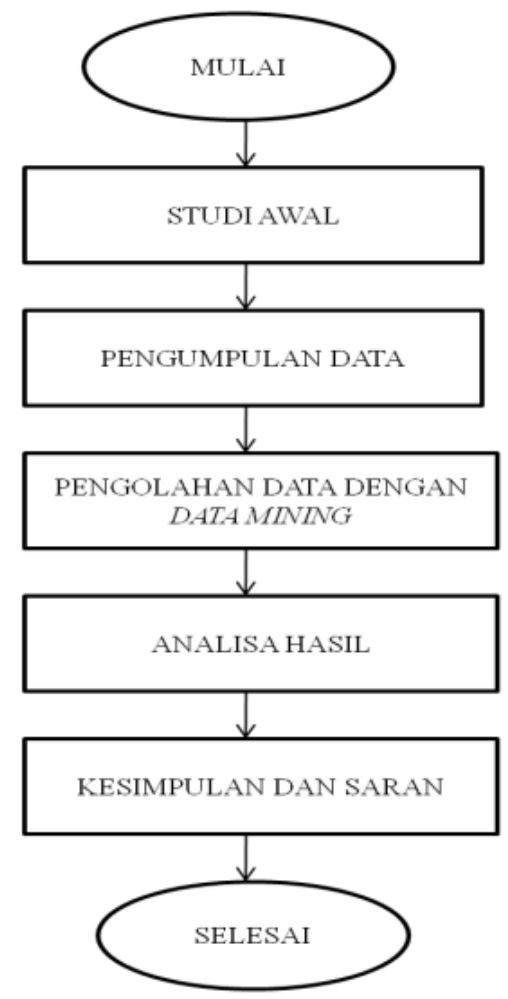

Penelitian ini diawali dengan melakukan studi awal guna mencari dan mempelajari masalah yang ada pada di PT. Agrinesia Raya Indonesia Kemudian menentukan ruang lingkup masalah, latar belakang masalah. Selanjutnya melakukan pengumpulan data penjualan produk lapis bogor sangkuriang periode September 2018 - Februari 2019 di PT. Agrinesia Raya Indonesia. Selanjutnya set data penjualan ini dilakukan pengolahan dengan terlebih dahulu melakukan identifikasi masalah yaitu, dengan mencari beberapa item set nilai support dan nilai confidence, yang sering dihadapi oleh PT. Agrinesia Raya Indonesia. Tahap selanjutnya dilakukan analisa masalah dengan tujuan agar dapat mengetahui dan memperoleh gambaran yang jelas bagaimana bentuk penyelesaian dan algoritma apa yang dapat digunakan untuk penyelesaiannya. Kemudian dilakukan dengan menggunakan teknik data mining dengan algoritma Apriori untuk mendapatkan hasil sebagai tujuan yang akan dicapai oleh peneliti yang kemudian dapat dijadikan pihak PT.Agrinesia Raya sebagai pengetahuan dalam meningkatkan penjualan produk lapis bogor sangkuriang kepada konsumen. Populasi daindonelam penelitian ini yaitu 8 rasa produk Lapis Bogor Sangkuriang yang di produksi oleh PT. Agrinesia Raya yang di jual di store yang terlihat pada tabel 1. Sedangkan sampel penelitian adalah Store Lapis Bogor Sangkuriang tersebar luas di sekitar wilayah Bogor. Untuk itu penelitian ini dilaksanakan di salah satu store yaitu tepatnya berada di Jalan Baru Bogor sebagai sampel penelitian.

Tabel 1

Sampel Data Produk Lapis Bogor Sangkuriang

\begin{tabular}{|c|l|}
\hline No. & Produk Lapis Bogor Sangkuriang \\
\hline 1 & Original Keju \\
\hline 2 & Full Talas Keju \\
\hline 3 & Cocopandan Keju \\
\hline 4 & Pisang Coklat \\
\hline 5 & Chocovila Keju \\
\hline 6 & Original Extra Chesse \\
\hline 7 & Kopi Susu \\
\hline 8 & Talas Susu \\
\hline \multicolumn{2}{|l|}{ Sumber $:($ Najib \& Suryani, 2019) } \\
\hline
\end{tabular}

Data penjualan yang di pilih merupakan data penjualan kue lapisada PT.Agrinesia Raya selama 6 bulan, dimulai pada September 2018 sampai Februari 2019. Berikut ini merupakan data penjualan:

1. Bulan September 2018

Sumber (Najib \& Suryani, 2019)

Gambar 1. Tahapan Penelitian 
Tabel 2

Data Penjualan Kue lapis Bulan September 2018

\begin{tabular}{|l|l|}
\hline Produk & Total \\
\hline Brownies Keju 550gr & 7369 \\
\hline Chocovila Keju 550gr & 3519 \\
\hline Coco Pandan Keju 550gr & 3325 \\
\hline Full Talas Keju 550gr & 4741 \\
\hline Kopi Susu 550gr & 1638 \\
\hline Original Extra Cheese 550gr & 1679 \\
\hline Original Keju 550gr & 19908 \\
\hline Pisang Cokelat 550gr & 3386 \\
\hline Teh Hijau Keju 550gr & 2001 \\
\hline
\end{tabular}

Sumber : (Najib \& Suryani, 2019)

Dari hasil penjualan kue lapis pada bulan September Original Keju 19.908 item terjual dan mendapatkan peringkat pertama paling tinggi kemudian disusul Brownies Keju

dengan 7.369 item dan posisi terakhir yang paling banyak dijual yaitu Full Talas Keju dengan 4.741 item.

2. Bulan Oktober 2019

Tabel 3

Data Penjualan Kue lapis Bulan Oktober 2018

\begin{tabular}{|l|l|}
\hline Produk & Total \\
\hline Brownies Keju 550gr & 6213 \\
\hline Chocovila Keju 550gr & 2648 \\
\hline Coco Pandan Keju 550gr & 2759 \\
\hline Full Talas Keju 550gr & 3350 \\
\hline Kopi Susu 550gr & 3438 \\
\hline Original Extra Cheese 550gr & 1052 \\
\hline Original Keju 550gr & 18086 \\
\hline Pisang Cokelat 550gr & 3238 \\
\hline Teh Hijau Keju 550gr & 1826 \\
\hline
\end{tabular}

Sumber : (Najib \& Suryani, 2019)

Dari hasil penjualan kue lapis pada bulan Oktober Original Keju 18.086 item kue lapis yang paling banyak terjual dan mendapatkan peringkat pertamapaling tinggi kemudian disusul Brownies Keju dengan 6.213 item dan posisi terakhir yang paling banyak dijual yaitu Kopi Susu dengan 3.438 item.

3. Bulan November 2018

Tabel 4

Data Penjualan Kue Lapis Bulan November 2018

\begin{tabular}{|l|l|}
\hline Produk & Total \\
\hline Brownies Keju 550gr & 6128 \\
\hline Chocovila Keju 550gr & 3388 \\
\hline Coco Pandan Keju 550gr & 3147 \\
\hline
\end{tabular}

\begin{tabular}{|l|l|} 
Full Talas Keju 550gr & 4433 \\
\hline Kopi Susu 550gr & 3503 \\
\hline Original Extra Cheese 550gr & 987 \\
\hline Original Keju 550gr & 19660 \\
\hline Pisang Cokelat 550gr & 3340 \\
\hline Teh Hijau Keju 550gr & 2311 \\
\hline
\end{tabular}

Sumber : (Najib \& Suryani, 2019)

Dari hasil penjualan kue lapis pada bulan November Original Keju 19.660 item terjual dan mendapatkan peringkat pertama paling tinggi kemudian disusul Brownies Keju dengan 6.128 item dan posisi terakhir yang paling banyak dijual yaitu Full Talas Keju dengan 4.433 item.

4. Bulan Desember 2018

Tabel 5

Data Penjualan Kue Lapis Bulan Desember 2018

\begin{tabular}{|l|l|}
\hline Produk & Total \\
\hline Brownies Keju 550gr & 4314 \\
\hline Chocovila Keju 550gr & 7257 \\
\hline Coco Pandan Keju 550gr & 4303 \\
\hline Full Talas Keju 550gr & 6200 \\
\hline Kopi Susu 550gr & 4457 \\
\hline Original Extra Cheese 550gr & 1187 \\
\hline Original Keju 550gr & 27587 \\
\hline Pisang Cokelat 550gr & 3633 \\
\hline Teh Hijau Keju 550gr & 3871 \\
\hline
\end{tabular}

Sumber: (Najib \& Suryani, 2019)

Dari hasil penjualan kue lapis pada bulan Desember Original Keju 27.587 item terjual dan mendapatkan peringkat pertama paling tinggi kemudian disusul Chocovila Keju dengan 7.257 item dan posisi terakhir yang paling banyak dijual yaitu Full Talas Keju dengan 6.200 item.

5. Bulan Januari 2019

Tabel 6

Data Penjualan Kue Lapis Bulan Januari 2019

\begin{tabular}{|l|l|}
\hline Produk & Total \\
\hline Brownies Keju 550gr & 3702 \\
\hline Chocovila Keju 550gr & 3366 \\
\hline Coco Pandan Keju 550gr & 5992 \\
\hline Full Talas Keju 550gr & 4673 \\
\hline Kopi Susu 550gr & 3094 \\
\hline Original Extra Cheese 550gr & 1637 \\
\hline Original Keju 550gr & 17095 \\
\hline Pisang Cokelat 550gr & 2344 \\
\hline Teh Hijau Keju 550gr & 2439 \\
\hline
\end{tabular}

Sumber : (Najib \& Suryani, 2019) 
Dari hasil penjualan kue lapis pada bulan Januari Original Keju 17.095 item terjual dan mendapatkan peringkat pertama paling tinggi kemudian disusul Cocopandan Keju dengan 5.992 item dan posisi terakhir yang paling banyak dijual yaitu Full Talas Keju dengan 4.673 item.

\section{Bulan Februari 2019}

Tabel 7

Data Penjualan Kue Lapis Bulan Februari 2019

\begin{tabular}{|l|l|}
\hline Produk & Total \\
\hline Brownies Keju 550gr & 4856 \\
\hline Chocovila Keju 550gr & 2606 \\
\hline Coco Pandan Keju 550gr & 3260 \\
\hline Full Talas Keju 550gr & 4534 \\
\hline Kopi Susu 550gr & 3223 \\
\hline Original Extra Cheese 550gr & 1100 \\
\hline Original Keju 550gr & 16226 \\
\hline Pisang Cokelat 550gr & 2204 \\
\hline Teh Hijau Keju 550gr & 656 \\
\hline Sumber :(Najb \& Suryani, 2019)
\end{tabular}

Sumber :(Najib \& Suryani, 2019)

Dari hasil penjualan kue lapis pada bulan Februari Original Keju 16.226 item terjual dan mendapatkan peringkat pertama paling tinggi kemudian disusul Brownies Keju dengan 4.856 item dan posisi terakhir yang paling banyak dijual yaitu Full Talas Keju dengan 4534 item.

Tahap dalam menganalisa data dengan algoritma apriori pada kue Lapis dimulai dengan menyeleksi dan membersihkan data-data yang akan dianalisis, kemudian dicari semua jenis item kue lapis yang ada didalam transaksi penjualan. Selanjutnya dicari jumlah setiap item yang ada pada transaksi penjualan.

\section{B. Pola Transaksi Penjualan Kue lapis Pada PT. Agrinesia Raya}

Berdasarkan data penjualan Kue lapis pada PT.Agrinesia Raya selama 6 bulan didapatkan pola transaksi dengan menganalisis 3 kue lapis yang paling banyak terjadi setiap bulannya, dapat dilihat pada Tabel 8.

\section{Tabel 8}

Pola Transaksi Penjualan Kue lapis

\begin{tabular}{|c|l|}
\hline Bulan & \multicolumn{1}{|c|}{ Item Set } \\
\hline 1 & $\begin{array}{l}\text { Original Keju, Brownies Keju, Full Talas } \\
\text { Keju }\end{array}$ \\
\hline 2 & Original Keju, Brownies Keju, Kopi Susu \\
\hline 3 & $\begin{array}{l}\text { Original Keju, Brownies Keju, Full Talas } \\
\text { Keju }\end{array}$ \\
\hline
\end{tabular}

\begin{tabular}{|c|l|}
\hline 4 & $\begin{array}{l}\text { Original Keju, Chocovila Keju, Full Talas } \\
\text { Keju }\end{array}$ \\
\hline 5 & $\begin{array}{l}\text { Original Keju, Cocopandan Keju, Full Talas } \\
\text { Keju }\end{array}$ \\
\hline 6 & $\begin{array}{l}\text { Original Keju, Brownies Keju, Full Talas } \\
\text { Keju }\end{array}$ \\
\hline
\end{tabular}

Sumber : (Najib \& Suryani, 2019)

\section{Melakukan Representasi Data Transaksi}

Representasi data transaksi dibuat berdasarkan data transaksi yang terdapat pada table 8 , representasi data tersebut dapat dilihat pada tabel dibawah ini:

Tabel 9

Representasi Data Transaksi

\begin{tabular}{|c|l|}
\hline Bulan & Item Yang Dibeli \\
\hline 1 & Original Keju \\
\hline 1 & Brownies Keju \\
\hline 1 & Full Talas Keju \\
\hline 2 & Original Keju \\
\hline 2 & Brownies Keju \\
\hline 2 & Kopi Susu \\
\hline 3 & Original Keju \\
\hline 3 & Brownies Keju \\
\hline 3 & Full Talas Keju \\
\hline 4 & Original Keju \\
\hline 4 & Chocovila Keju \\
\hline 4 & Full Talas Keju \\
\hline 5 & Original Keju \\
\hline 5 & Cocopandan Keju \\
\hline 5 & Full Talas Keju \\
\hline 6 & Original Keju \\
\hline 6 & Brownies Keju \\
\hline 6 & Full Talas Keju \\
\hline
\end{tabular}

Sumber : (Najib \& Suryani, 2019)

\section{Pembuatan FormatTabular}

Format tabular data transaksi bulanan bila dibentuk akan tampak seperti tabel dibawah ini:

Tabel 10

Format Tabular Data Transaksi

\begin{tabular}{|l|c|c|c|c|c|c|}
\hline \multirow{2}{*}{\multicolumn{1}{c|}{ Kue }} & \multicolumn{6}{c|}{ Bulan } \\
\cline { 2 - 7 } & 1 & 2 & 3 & 4 & 5 & 6 \\
\hline Original keju & 1 & 1 & 1 & 1 & 1 & 1 \\
\hline Brownies keju & 1 & 1 & 1 & 0 & 0 & 1 \\
\hline Kopi susu & 0 & 1 & 0 & 0 & 0 & 0 \\
\hline Original extra chesse & 0 & 0 & 0 & 0 & 0 & 0 \\
\hline Chocovila keju & 0 & 0 & 0 & 1 & 0 & 0 \\
\hline Cocopandan keju & 0 & 0 & 0 & 0 & 1 & 0 \\
\hline Pisang coklat & 0 & 0 & 0 & 0 & 0 & 0 \\
\hline Full talas & 1 & 0 & 1 & 1 & 1 & 1 \\
\hline Teh hijau keju & 0 & 0 & 0 & 0 & 0 & 0 \\
\hline
\end{tabular}

Sumber : (Najib \& Suryani, 2019) 


\section{E. Analisa Pola Frekuensi}

\section{Pembentukan 1 Itemset}

Berikut ini adalah penyelesaian dengan contoh kasus berdasarkan data yang sudah disediakan. Proses pembentukan $\mathrm{C}_{1}$ atau disebut dengan 1 itemset dengan jumlah minimun support $=30 \%$ yang terlihat pada tabel 11. Dengan rumus sebagai berikut:

$\operatorname{Support}(A)=\frac{\sum \text { transahsi mengandung } A}{\sum \text { transaksi }} * 100 \%$

Tabel 11

Support Dari Tiap Itemset

\begin{tabular}{|l|l|}
\hline Itemset & Support \\
\hline Original Keju & $100 \%$ \\
\hline Brownies Keju & $66 \%$ \\
\hline Full Talas Keju & $83 \%$ \\
\hline Kopi Susu & $16 \%$ \\
\hline Chocovila Keju & $16 \%$ \\
\hline Cocopan dan Keju & $16 \%$ \\
\hline
\end{tabular}

Sumber : (Najib \& Suryani, 2019)

Minimal Support yang ditentukan adalah 30\%, jadi kombinasi 1 itemset yang tidak memenuhi minimal suppport akan dihilangkan, bisa dilihat seperti tabel dibawah ini:

Tabel 12

Minimal Support 1Itemset 30\%

\begin{tabular}{|l|l|}
\hline Itemset & Support \\
\hline Original Keju & $100 \%$ \\
\hline Brownies Keju & $66 \%$ \\
\hline Full Talas Keju & $83 \%$ \\
\hline
\end{tabular}

Sumber : (Najib \& Suryani, 2019)

\section{Kombinasi 2 Itemset}

Proses pembentukan $\mathrm{C}_{2}$ atau disebut dengan 2 itemset dengan jumlah minimum support $30 \%$ dengan rumus sebagai berikut:

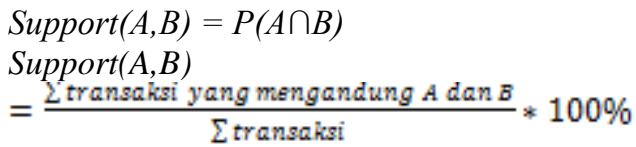

Tabel 13

Support dan Kombinasi 2 Itemset

\begin{tabular}{|l|l|}
\hline Itemset & Support \\
\hline Original Keju, Brownies Keju & $\mathbf{6 6 . 7 \%}$ \\
\hline Original Keju, Full TalasKeju & $\mathbf{8 3 . 3 \%}$ \\
\hline Original Keju, Kopi Susu & $16 \%$ \\
\hline $\begin{array}{l}\text { Original Keju, Cocopan dan } \\
\text { Keju }\end{array}$ & $16 \%$ \\
\hline $\begin{array}{l}\text { Original Keju, Chocovila } \\
\text { Keju }\end{array}$ & $16 \%$ \\
\hline Brownies Keju, Full Talas & $\mathbf{5 0 \%}$ \\
\hline
\end{tabular}

\begin{tabular}{|l|l|}
\hline Brownies Keju, Kopi Susu & $16 \%$ \\
\hline Full Talas, Kopi Susu & $16 \%$ \\
\hline Full Talas, Cocopan dan Keju & $16 \%$ \\
\hline Full Talas, Chocovila & $16 \%$ \\
\hline
\end{tabular}

Sumber : (Najib \& Suryani, 2019)

Minimal Support yang ditentukan adalah $30 \%$, jadi kombinasi 2 itemset yang tidak memenuhi minimal suppport akan dihilangkan, bisa dilihat seperti tabel dibawah ini:

Tabel 14

Minimal Support 2 Itemset $30 \%$

\begin{tabular}{|l|l|}
\hline Itemset & Support \\
\hline Original Keju, Brownies Keju & $\mathbf{6 6 . 7 \%}$ \\
\hline Original Keju, Full TalasKeju & $\mathbf{8 3 . 3 \%}$ \\
\hline Brownies Keju, Full Talas & $\mathbf{5 0 \%}$ \\
\hline
\end{tabular}

Sumber : (Najib \& Suryani, 2019)

\section{Kombinasi 3 Itemset}

Proses pembentukan $\mathrm{C}_{3}$ atau disebut dengan 3 itemset dengan jumlah minimal support $30 \%$ dengan rumus sebagai berikut:

$\operatorname{Support}(A, B)=P(A \cap B \cap C)$

Support(A,B dan $C)=\frac{\text { Ztransahsi yang mengandung } A_{J} B \text { dan } C}{\sum \text { transaksi }} * 100 \%$

Tabel 15

Support dari 3 kombinasi 3 itemset

\begin{tabular}{|l|l|}
\hline Itemset & Support \\
\hline $\begin{array}{l}\text { Original Keju, Brownies Keju, } \\
\text { Full Talas }\end{array}$ & $\mathbf{5 0 \%}$ \\
\hline $\begin{array}{l}\text { Original Keju, Brownies Keju, } \\
\text { Kopi Susu }\end{array}$ & $\mathbf{1 6 \%}$ \\
\hline $\begin{array}{l}\text { Original Keju, Brownies Keju, } \\
\text { Chocovila }\end{array}$ & $\mathbf{0 \%}$ \\
\hline $\begin{array}{l}\text { Original Keju, Brownies Keju, } \\
\text { Coco Pandan Keju }\end{array}$ & $\mathbf{0 \%}$ \\
\hline $\begin{array}{l}\text { Original Keju, Full Talas Keju, } \\
\text { Chocovila }\end{array}$ & $\mathbf{1 6 \%}$ \\
\hline $\begin{array}{l}\text { Original Keju, Full Talas Keju, } \\
\text { Coco Pandan Keju }\end{array}$ & $\mathbf{1 6 \%}$ \\
\hline $\begin{array}{l}\text { Original Keju, Full Talas Keju, } \\
\text { Kopi Susu }\end{array}$ & $\mathbf{0 \%}$ \\
\hline
\end{tabular}

Sumber : (Najib \& Suryani, 2019)

Selanjutnya dilakukan pengolahan data 3 itemset dengan jumlah minimin $30 \%$ dengan hasil yang tertera pada tabel 16 dibawah ini

Tabel 16

Minimal Support 3 Itemset $30 \%$

\begin{tabular}{|l|l|}
\hline Itemset & Support \\
\hline $\begin{array}{l}\text { Original Keju, Brownies Keju, Full } \\
\text { Talas }\end{array}$ & $50 \%$ \\
\hline
\end{tabular}

Sumber : (Najib \& Suryani, 2019) 


\section{F. Pembentukan Aturan Asosiasi}

Setelah semua pola frekuensi tinggi ditemukan, barulah dicari aturan asosiasi dengan hasil pola frekuensi sebagai berikut:

Tabel 17

Hasil pola frekuensi tinggi yang memenuhi syarat

\begin{tabular}{|l|l|}
\hline Itemset & Support \\
\hline Original Keju, Brownies Keju & $\mathbf{6 6 . 7 \%}$ \\
\hline Original Keju, Full TalasKeju & $\mathbf{8 3 . 3 \%}$ \\
\hline Brownies Keju, Full Talas & $\mathbf{5 0 \%}$ \\
\hline $\begin{array}{l}\text { Original Keju, Brownies Keju, Full } \\
\text { Talas }\end{array}$ & $\mathbf{5 0 \%}$ \\
\hline
\end{tabular}

Sumber : (Najib \& Suryani, 2019)

Karena 4 itemset yang memenuhi syarat minimum support maka nilai confindence yang di cari 2 kombinasi itemset dan 3 kombinasi itemset.

Setelah semua pola frekuensi tinggi di temukan, barulah di cari aturan asosiasi yang memenuhi syarat minimum untuk confidence dengan menhitung confidence atau asosiatif $\mathrm{A} \rightarrow \mathrm{B}$, dengan minumum confidence $70 \%$.

Nilai confidence aturan $\mathrm{A} \rightarrow \mathrm{B}$ di didaptkan dari:

Confidence $=\mathrm{P}(\mathrm{B} / \mathrm{A})$

$=\frac{\sum \text { transaksi yang mengandung } A \text { dan } B}{\sum \text { transaksi mengandung } A} * 100 \%$

Confidence $=\mathrm{P}($ Original $/$ Brownies $)$

Etransaksi yang mengandung Original dan Brownies

$=\frac{}{\sum \text { transaksi }} * 100 \%$

$\sum$ transaksi yang mengandung Original

$$
=\frac{4}{6} * 100 \%=66,66 \%
$$

Confidence $=\mathrm{P}($ Brownies $/$ Original $)$

$\sum$ transaksi yang mengandung Original dan Brownies

$=\frac{\text { Etransaksi yang mengandung Brownies }}{100}$

$$
=\frac{4}{4}+100 \%=100 \%
$$

Confidence $=\mathrm{P}($ Original $/$ Full Talas $)$

Stransaksi yang mengandung Original dan Full Talas

$=$ Etransaksi yang mengandung Original

$$
=\frac{5}{6}+100 \%=83,33 \%
$$

Confidence $=\mathrm{P}($ Full Talas $/$ Original $)$

Stransaksi yang mengandung Original dan Full Talas

$=\overline{\text { Stransaksi yang mengandung Full Talas }}$

$$
={ }_{5}^{5} * 100 \%=100 \%
$$

Confidence $=\mathrm{P}($ Brownies $/$ Full Talas $)$

$\sum$ transaksi yang mengandung Brownies dan Full Talas

$=\overline{\sum \text { transaksi yang mengandung Brownies }}$

$$
=\frac{3}{4} * 100 \%=75 \%
$$

Confidence $=\mathrm{P}($ Full Talas $/$ Brownies $)$

Stransaksi yang mengandung Full Talas dan Brownies

$=\overline{\text { Stransaksi yang mengandung Full Talas }}$

$$
=\frac{3}{5} * 100 \%=60 \%
$$

Confidence $=\mathrm{P}($ Original,Full Talas, Brownies $)$ Stransaksi yang mengandung Original, Full Talas dan Brownies

Etransaksi yang mengandung Original dan Full Talas

$$
=\frac{3}{5} * 100 \%=60 \%
$$

Confidence $=\mathrm{P}($ Original, Brownies, Full Talas $)$

Stransaksi yang mengandung Original, Brownies, dan Full Talas

$=\overline{\text { Etransaksi yang mengandung Original }}$

$$
={ }^{3} * 100 \%=75 \%
$$

Hasil asosiasi dari perhitungan diatas terlihat pada tabel dibawah ini 
Tabel 18

Hasil Asosiasi dari F2

\begin{tabular}{|l|c|c|}
\hline \multicolumn{2}{|c|}{ Aturan } & \multicolumn{2}{c|}{ Confidence } \\
\hline $\begin{array}{l}\text { Jika membeli Original Keju,maka } \\
\text { akan membeli Brownies Keju }\end{array}$ & $4 / 6$ & $66,66 \%$ \\
\hline $\begin{array}{l}\text { Jika membeli Brownies Keju } \\
\text {,maka akan membeli Original Keju }\end{array}$ & $4 / 4$ & $\mathbf{1 0 0 \%}$ \\
\hline $\begin{array}{l}\text { Jika membeli Original Keju ,maka } \\
\text { akan membeli Full Talas Keju }\end{array}$ & $5 / 6$ & $\mathbf{8 3 . 3 3 \%}$ \\
\hline $\begin{array}{l}\text { Jika membeli Full Talas Keju } \\
\text { maka akan membeli Original Keju }\end{array}$ & $5 / 5$ & $\mathbf{1 0 0 \%}$ \\
\hline
\end{tabular}

Jika membeli Brownies Keju,maka akan membeli Full Talas Keju

Jika membeli Full Talas Keju,maka akan membeli Brownies Keju

Jika membeli Original Keju dan

Brownies Keju , maka akan membeli Full Talas Keju

Jika membeli Original Keju dan

Full Talas Keju , maka akan

membeli Brownies Keju

Sumber :(Najib \& $\quad$ Suryani, 2019)

\section{G. Implementasi Algoritma Pada Tanagra}

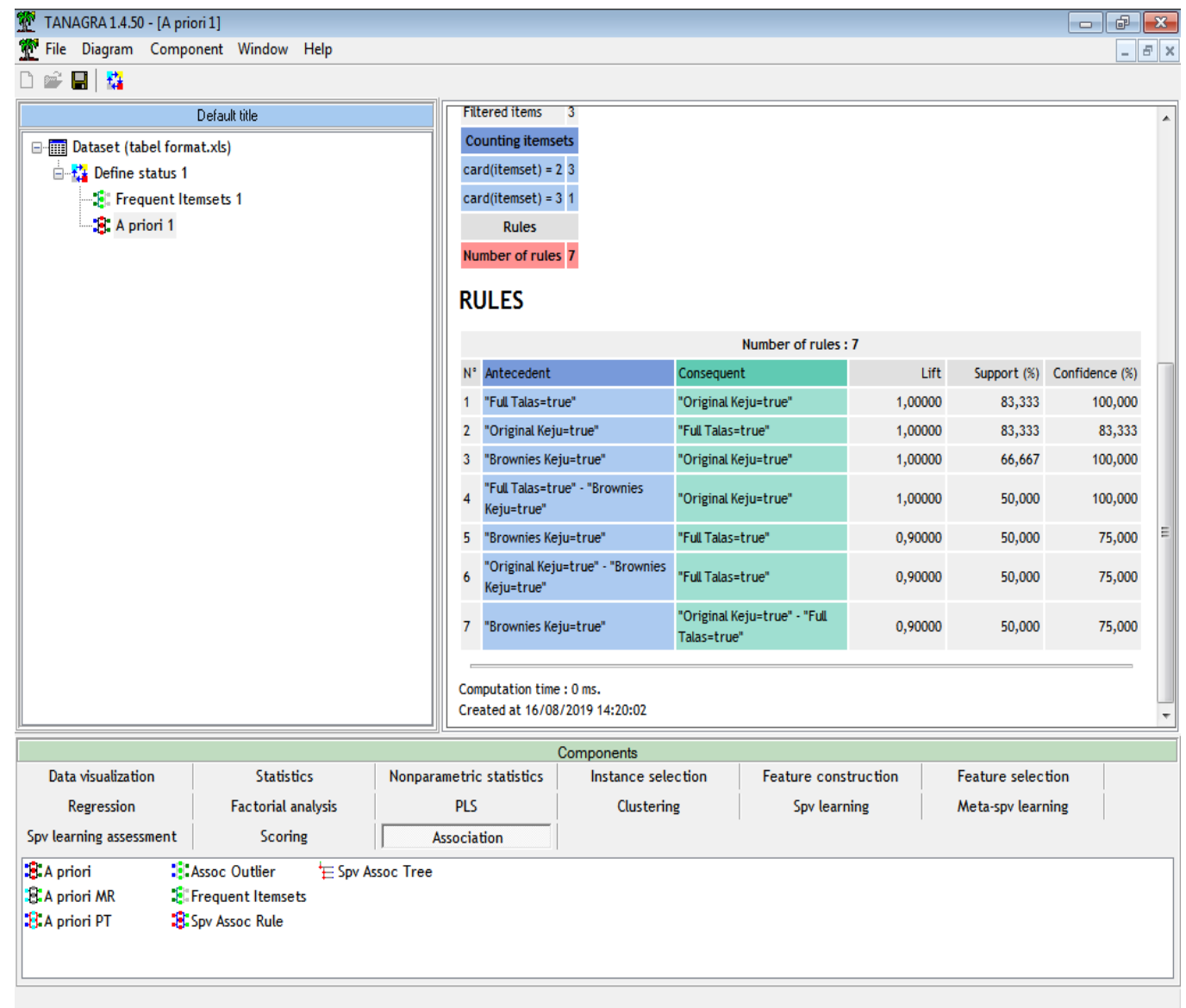

Sumber : (Najib \& Suryani, 2019)

Gambar 2. Hasil Asosiasi Final 
Dari gambar diatas terlihat hasil dari asosiasi final yang memenuhi minimal support dan minimal confidence, yang memenuhi support dan confidence adalah Original Keju, Full Talas, Brownies Keju.

Aturan asosiasi final terurut berdasarkan minimal support dan minimal confidence yang telah di tentukan, dapat di lihat pada tabel di bawah ini:

Tabel 19

Aturan Asosiasi Final

\begin{tabular}{|l|c|c|}
\hline Aturan & \multicolumn{2}{|c|}{ Confidence } \\
\hline $\begin{array}{l}\text { Jika membeli Original Keju,maka akan } \\
\text { membeli Brownies Keju }\end{array}$ & $4 / 6$ & $66,66 \%$ \\
\hline $\begin{array}{l}\text { Jika membeli Brownies Keju ,maka } \\
\text { akan membeli Original Keju }\end{array}$ & $4 / 4$ & $\mathbf{1 0 0 \%}$ \\
\hline $\begin{array}{l}\text { Jika membeli Original Keju ,maka } \\
\text { akan membeli Full Talas Keju }\end{array}$ & $5 / 6$ & $\mathbf{8 3 . 3 3 \%}$ \\
\hline $\begin{array}{l}\text { Jika membeli Full Talas Keju ,maka } \\
\text { akan membeli Original Keju }\end{array}$ & $5 / 5$ & $\mathbf{1 0 0 \%}$ \\
\hline $\begin{array}{l}\text { Jika membeli Brownies Keju ,maka } \\
\text { akan membeli Full Talas Keju }\end{array}$ & $3 / 4$ & $\mathbf{7 5 \%}$ \\
\hline $\begin{array}{l}\text { Jika membeli Full Talas Keju ,maka } \\
\text { akan membeli Brownies Keju }\end{array}$ & $3 / 5$ & $60 \%$ \\
\hline $\begin{array}{l}\text { Jika membeli Original Keju dan } \\
\text { Brownies Keju, maka akan membeli }\end{array}$ & & \\
Full Talas Keju & $3 / 5$ & $60 \%$ \\
\hline $\begin{array}{l}\text { Jika membeli Original Keju dan Full } \\
\text { Talas Keju, maka akan membeli } \\
\text { Brownies Keju }\end{array}$ & $3 / 4$ & $\mathbf{7 5 \%}$ \\
\hline
\end{tabular}

Sumber: (Najib \& Suryani, 2019)

\section{KESIMPULAN}

Penelitian ini dilakukan agar mengetahui produk apa saja yang paling banyak terjual dengan melihat produk/item yang memenuhi minimum support dan minimum confidences sehingga membantu perusahaan dalam mengembangkan strategi pemasaran dengan promosi dan memberikan informasi untuk mengantisipasi kekosongan stok barang. Produk yang paling banyak terjual untuk kue lapis adalah Original Keju, Brownies Keju, Full Talas. Berdasarkan aturan asosiasi final yang diketahui jika membeli kue Lapis Bogor Sangkuriang varian Original Keju maka akan membeli Lapis Bogor Sangkuriang varian Brownies Keju dan Full Talas Keju dengan nilai support $30 \%$ dan nilai confidence $70 \%$. Penelitian ini masih perlu disempurnakan kareanya disarankan sebagai berikut:

1. Pengembangan penelitian dengan metode berbeda dengan nilai support dan nilai confidence yang lebih optimal.

2. Perlu penggunakan set data penjualan yang lebih luas agar olahan data yang dihasilkan lebih optimal.

\section{REFERENSI}

Aprianti, W., Permadi, J., \& Oktaviyani. (2017).
Penerapan Algoritma Apriori untuk Transaksi Penjualan Obat pada Apotek Azka. Seminar Nasional Matematika Dan Aplikasinya, 436442.

Gunadi, G., \& Sensuse, D. I. (2012). Penerapan Metode Data Mining Market Basket Analysis Terhadap Data Penjualan Produk Buku Dengan Menggunakan Algoritma Apriori Dan Frequent Pattern Growth ( Fp-Growth): Telematika, 4(1), 118-132.

Halim, J. (1917). Penerapan Data Mining Untuk Mengukur Tingkat Kepuasan Siswa Terhadap Pelayanan Di Bimbingan Belajar Al-Misbah Dengan. SAINTIKOM Vol. 16, No. 1, 16(1), 1$6 . \quad$ Retrieved from https://prpm.trigunadharma.ac.id/public/fileJur nal/hplH11 Jufri.pdf

Hidayat, A. Z., \& Wijanarto. (2017). Dokumen Karya Ilmiah | Skripsi | Prodi Teknik Informatika - S1 | FIK | UDINUS | 2016. Fik, 1(1), 1-2. https://doi.org/10.1021/jf901375e

Najib, B. A., \& Suryani, N. (2019). LAPORAN PENELITIAN: PENERAPAN DATA MINING ANALISIS TERHADAP DATA PENJUALAN LAPIS BOGOR SANGKURIANG DENGAN METODE ALGORITMA APRIORI. Jakarta: STMIK NUSA MANDIRI.

Nursikuwagus, A., \& Hartono, T. (2016). Implementasi Algoritma Apriori Untuk Analisis Penjualan Dengan Berbasis Web. Simetris: Jurnal Teknik Mesin, Elektro Dan Ilmu Komputer, 7(2), 701. https://doi.org/10.24176/simet.v7i2.784

Rahmawati, F., \& Merlina, N. (2018). Metode Data Mining Terhadap Data Penjualan Sparepart Mesin Fotocopy Menggunakan Algoritma Apriori. PIKSEL : Penelitian Ilmu Komputer Sistem Embedded and Logic, 6(1), 9-20. https://doi.org/10.33558/piksel.v6i1.1390

Ristianingrum, \& Sulastri. (2017). Implementasi Data Mining Menggunakan Algoritma Apriori. Prosiding SINTAK 2017, 2(2), 372-382.

Sianturi, F. A. (2018). Penerapan Algoritma Apriori Untuk Penentuan Tingkat Pesanan. Mantik Penusa, 2(1), 50-57. Retrieved from http://ejurnal.pelitanusantara.ac.id/index.php/mantik/a rticle/view/330

Siregar, S. R. (2014). IMPLEMENTASI DATA MINING PADA PENJUALAN TIKET PESAWAT MENGGUNAKAN ALGORITMA APRIORI ( Studi Kasus : Jumbo Travel Medan ). Pelita Informatika Budi Darma, Volume Vii, Nomor 1, Juli 2014, VII(1), 152-156.

Syahdan, S. Al, \& Sindar, A. (2018). Data Mining Penjualan Produk Dengan Metode Apriori Pada Indomaret Galang Kota. Jurnal Nasional Komputasi Dan Teknologi Informasi (JNKTI), 1(2). https://doi.org/10.32672/jnkti.v1i2.771 